\title{
DESENVOLVIMENTO DE UM AMBIENTE PROPÍCIO PARA INOVAÇÃO NO SETOR DE SERVIÇOS: UMA ANÁLISE EM EMPRESAS DE SERVIÇOS CONTÁBEIS DO VALE DO ITAJAÍ - SC
}

\section{DEVELOPMENT OF PROPITIOUS ENVIRONMENT FOR INNOVATION IN THE SERVICE SECTOR: AN ANALYSIS OF ACCOUNTING BUSINESSES IN ITAJAÍ VALLEY - SC-BRAZIL}

\section{Marcia Regina Santiago Scarpin ${ }^{a}$; Luis Cesar Mondini ${ }^{b}$; Mariana Neumann ${ }^{c}$; Denise Del Prá Netto Machado ${ }^{d}$}

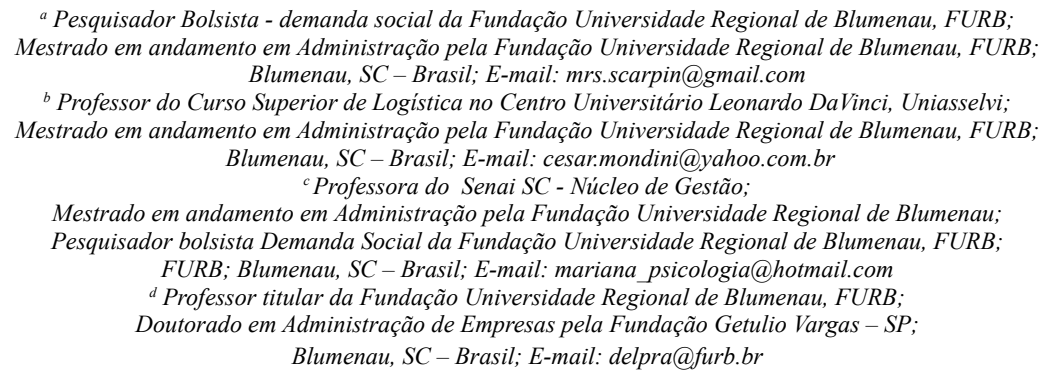
Blumenau, SC-Brasil; E-mail: delpra@furb.br

\section{Resumo}

O presente estudo buscou verificar a percepção dos colaboradores e gestores de escritórios contábeis no que se refere a ambientes propícios ao desenvolvimento de inovação. Para tanto se escolheu realizar uma pesquisa quantitativa descritiva transversal, com levantamento de dados primários por meio de questionários. Para aplicação da pesquisa foram selecionados cinco escritórios contábeis da cidade de Gaspar, localizada no Vale do Itajaí, Santa Catariana. Três deles possuem onze colaboradores, um nove, e o último, oito, totalizando 50 (cinquenta) funcionários. Dados coletados foram tratados pela análise de componentes principais (ACP). Como principais resultados observou-se que as características que os funcionários dos escritórios contábeis percebem como influenciadores em um ambiente que promova a inovação estão ligados às dimensões: D1 - relacionamento interno; D2 - recursos; D3 - liderança e D4 - resolução de conflito.

Palavras-chave: Inovação, Ambiente, Serviços Contábeis.

\section{Abstract}

This study aimed to verify the perception of employees and managers in accounting offices regarding the development of propitious environments toward innovation. We chose to carry a cross quantitative-descriptive survey with primary data collection through questionnaire. For research appliance there were selected five accounting offices of the city of Gaspar, located in the Itajai Valley, Santa Catarina, Brazil. Three of them have eleven employees, one has nine and the last one has eight, totalizing 50 (fifty) employees. The collected data was treated by principal component analysis (PCA). As main results it was observed that the features that accounting office workers perceive as influencing a propitious environment toward innovation are linked to the dimensions: D1 - internal relationship; D2 - resources; D3 - leadership and D4 - conflict resolution.

Keywords: Innovation, Environment, Accounting Services. 
Desenvolvimento de um Ambiente Propício para Inovação no Setor de Serviços: uma Análise em Empresas de Serviços Contábeis do Vale do Itajaí - SC

\section{INTRODUÇÃO}

O contexto organizacional atual vivência uma crescente competitividade, tornando as empresas mais preocupadas e ativas em desenvolver um conjunto de competências para enfrentar a concorrência e garantir sua permanência no mercado. Para obter vantagens competitivas sustentáveis, as organizações precisam lançar produtos e serviços inovadores, atendendo as expectativas de seus consumidores em relação ao design, a funcionalidade, a qualidade e ao preço.

Com o avançado crescimento do setor terciário, algumas abordagens tradicionais que consideram as atividades de serviços pouco tecnológicas e passivas dos conhecimentos gerados na indústria estão sendo confrontadas. Evidências empíricas indicam um crescimento expressivo deste setor no desenvolvimento de tecnologia e geração de conhecimento (BERNARDES; BESSA; KALUP, 2005).

A inovação como uma ideia + ação = resultado de Gundling (1999), abrange também as empresas prestadoras de serviços, que em muitos casos acreditam que a inovação é algo específico das indústrias. Essa crença se fundamenta na percepção de que a indústria provê tecnologia e gera patentes.

Prestadoras de serviços, como escritórios contábeis, desenvolvem processos que envolvem inovações constantes. Um exemplo é o portfólio de serviços prestados, que abrange desde consultoria contábil, auditoria, perícias, cálculos judiciais, até assessorias diversas que necessitam de adequações constantes às normas contábeis direcionadas pelo governo, para melhor atender seus clientes.

O objetivo da contabilidade é possibilitar que os fatos operacionais das organizações sejam traduzidos em expressões monetárias, fornecendo assim, uma visão geral da sua situação econômica e financeira. A contabilidade moderna deve servir de ferramenta para a tomada de decisão dos usuários e ser capaz de atender plenamente os seus anseios (IUDÍCIBUS, 2000).

Apesar de bastante padronizados pela legislação, os processos dos escritórios contábeis, assim como os da maioria das organizações precisam alinhar-se às exigências do mercado para manterem-se competitivos (FRANCO, 1990). Assim, as inovações mais perceptíveis no ambiente contábil são de ordem tecnológica, as quais propiciam maior eficiência e melhor gestão dos negócios empresariais a todos os seus clientes. Os processos adotados no cotidiano dessas organizações sofrem influência constante da evolução da tecnologia. Esses avanços resultam em maior agilidade e precisão das informações fornecidas e orientação mais apurada aos usuários contábeis (PEGORARO, 2007).

Com a finalidade de contribuir com as pesquisas sobre inovação em serviços, a proposta deste estudo possui a seguinte questão de pesquisa: quais são as características relacionadas à inovação percebidas pelos funcionários de um grupo de escritório contábil? Para responder a essa pergunta o estudo tem como objetivo verificar a percepção dos colaboradores e gestores de escritórios contábeis no que se refere à ambientes propícios ao desenvolvimento de inovação.

Para tanto, este estudo encontra-se estruturado com mais quatro seções, além desta primeira, que é a introdução. Na segunda, como referencial teórico, destacam-se: o setor de serviços; inovação no setor de serviços e ambientes propícios para inovação. A terceira é a 
seção destinada à metodologia da pesquisa. Na quarta, apresentam-se as análises dos dados. E, por fim, a quinta seção destina-se às considerações finais e a sugestões de futuras pesquisas.

\section{REVISÃO DA LITERATURA}

\subsection{Setor de serviços}

As tentativas para o estabelecimento de uma definição precisa das atividades de serviço remontam aos primórdios da ciência econômica, a partir das tentativas de definir os fundamentos do trabalho (DELAUNAY; GANDREY, 1987; KON, 1999), e também repassam os estudos organizacionais (GRÖNROSS, 1993). Para Kotler (2000, p. 448) serviços podem ser definidos como "qualquer ato ou desempenho, essencialmente intangível, que uma parte pode oferecer a outra e que não resulta na propriedade de nada".

Ainda segundo o autor, os serviços apresentam quatro características básicas:

1. Intangibilidade: ao contrário de produtos físicos, os serviços não podem ser vistos, sentidos, ouvidos, cheirados ou provados antes de serem adquiridos.

2. Inseparabilidade: de um modo geral, os serviços são produzidos e consumidos ao mesmo tempo.

3. Variabilidade: pelo fato de dependerem de quem os fornece, além de onde e quando são fornecidos, os serviços são altamente variáveis.

4. Perecibilidade: serviços não podem ser estocados. (KOTLER, 2000, p. 439)

A produção de um serviço difere da produção de um produto em relação aos profissionais. Enquanto que para um produto a preparação profissional fica restrita ao posto de trabalho, para a produção de serviços é necessário uma qualificação profissional mais ampla (ZARIFIAN, 2001).

Miles (2001) identificou três movimentos de transformações estruturais que transcorre a economia de serviços, apresentando uma compreensão crítica para o desenvolvimento de um processo de inovação setorial.

A primeira refere-se aos serviços físicos, na qual a transformação provém das tecnologias de informação e comunicação (TICs), atuando diretamente na forma de preservação intemporal e/ou transporte de serviços, bens e pessoas. Como exemplo, os serviços de logística para distribuição, movimentação e estocagem de produtos.

A segunda relaciona os serviços personalizados, que são apresentados em dois grupos distintos, os serviços comunitários e sociais e os serviços de consumo privado. A propagação das TICs e inovações organizacionais têm proporcionado um grande avanço na integração dos processos gerenciais, na qualidade e na produtividade destes serviços. Nessa classe é possível relacionar os serviços comunitários e sociais a saúde e educação, bem como os salões de beleza e hotéis.

E, por último, os serviços informacionais, que se dividem em três tipos de atividades:

a) Mídia de massa, identificada pela distribuição padronizada em escala de informações audiovisuais. Ex.: a televisão e o cinema.

b) Infomídia, que apresenta as mesmas características dos serviços informacionais, 
porém, a distribuição de informações customizadas e personalizadas acontece em larga escala, tais como os serviços de telefonia com imagem.

c) Serviços intensivos em conhecimento, que se utiliza do conhecimento e da informação especializada, bem como a expertise profissional para a capacidade de codificação, interpretação e análise de dados. As empresas de engenharia, arquitetura e consultorias, entre outras, são exemplos desta atividade (MILES, 2001).

Dentre os serviços informacionais, encontram-se os serviços contábeis, voltado às atividades em serviços intensivos de conhecimento, pois possuem como fator crucial o conhecimento e a informação especializada. Com isso, permitem verificar se os controles internos adotados retratam as mutações patrimoniais e se houve algum erro ou fraudes em algum ponto do processo. Para Peleias (1999, p. 3), a contabilidade é "um instrumento que deve capturar informações corretas, completas e acuradas sobre todas as transações, bens, direitos e obrigações que compõe a atividade empresarial, ou que delas derivam”.

Os serviços contábeis geram informações importantes para as análises dos usuários, que poderão utilizá-las como parâmetro em políticas de investimento, por interferir no processo de tomada de decisão dos investidores e credores, bem como, nas decisões de investimentos dos administradores (MARTINEZ, 2001, COLAUTO; BEUREN, 2004). Corroborando esta ideia, Sunder (1997) defende que as informações contábeis se apresentam como fundamentais para análise sobre a continuidade e viabilidade da organização.

O crescimento das atividades em serviços vem crescendo na economia, dessa forma é necessário atentar para processos de inovação que favoreçam o consumidor final, e garanta a competitividade para as empresas do ramo.

\subsection{Inovação no setor de serviços}

A inovação pode ser entendida como a adoção de uma ideia já existente, mas que é nova para a organização que a está adotando, incluindo novos produtos, serviços, tecnologias, processos, procedimentos, sistemas ou arranjos sociais (DOSI, 1982; DAMANPOUR, 1991; AFUAH, 2003). Damanpour (1991) complementa o conceito incorporando ao contexto novos comportamentos, uma nova estrutura ou sistema administrativo e um novo plano ou programa relativo aos membros da organização, os quais, quando ligados à gestão, trabalham para transformar input em output (HAMEL, 2006).

Além de uma ideia, a inovação é uma prática ou um bem material que é percebido como novo e de relevante aplicação conforme destacado por Zaltman, Duncann e Holbek (1973), podendo esta ser baseada no uso de um novo conhecimento tecnológico ou de mercado para oferecer produtos ou serviços novos aos clientes. Nesse caso, considera-se novo quando se consegue baixar seu custo, seus atributos são melhorados, ou ainda quando eles são inexistentes no mercado (AFUAH, 2003).

Segundo Tigre (2006) e Tidd, Bessant e Pavitt (2008) a inovação em serviços destaca-se em relação ao produto, pois os serviços apresentam-se de forma intangível, enquanto os produtos geralmente são tangíveis. Como as funções de serviços são, por essência, complementares a outros produtos, com frequência termos como "produto da inovação em serviços" e "produto 
de inovações" tem sido utilizados para descrever uma série de inovações em serviços (OKE, 2007). Isso também pode ocorrer, pois são relativamente recentes os estudos empíricos sobre inovação no setor de serviços (DREJER, 2004).

Howells (2000) apresenta no Quadro 01, os diferentes aspectos do processo de convergência e diferenciação das trajetórias de inovação nos serviços e na indústria.

\begin{tabular}{|c|c|c|c|}
\hline Características & Indústria & Serviços & Status \\
\hline $\begin{array}{l}\text { 1. Direitos de } \\
\text { propriedade } \\
\text { intelectual }\end{array}$ & Forte: Patentes & Fraco: Direitos autorais & Corrente, forte \\
\hline $\begin{array}{l}\text { 2. Orientação } \\
\text { tecnológica }\end{array}$ & $\begin{array}{c}\text { Avanço tecnológico; } \\
\text { liderança cientifica e } \\
\text { tecnológica }\end{array}$ & $\begin{array}{c}\text { Avanço tecnológico; } \\
\text { liderança fornecedor/ } \\
\text { cliente }\end{array}$ & Histórico, declinante \\
\hline $\begin{array}{l}\text { 3. Pesquisa/Inovação } \\
\text { provedor e fornecedor }\end{array}$ & Internamente & Provido externamente & $\begin{array}{c}\text { Declinante; } \\
\text { convergindo na } \\
\text { indústria e serviços }\end{array}$ \\
\hline 4. Força produtiva & Alto impacto & Baixo impacto & Declinante, forte \\
\hline 5. Ciclos de inovação & Curto e médio & $\begin{array}{c}\text { Longo (exceto ao serviço } \\
\text { de informática) }\end{array}$ & Declinante, forte \\
\hline $\begin{array}{l}\text { 6. Características do } \\
\text { produto }\end{array}$ & $\begin{array}{c}\text { Tangível, de fácil } \\
\text { estocagem }\end{array}$ & $\begin{array}{l}\text { Intangível, de difícil } \\
\text { estocagem }\end{array}$ & Declinante, médio \\
\hline 7. Internacionalização & $\begin{array}{l}\text { A atividade de exportação } \\
\text { atrai o Investimento } \\
\text { Estrangeiro Direto (IED) }\end{array}$ & $\begin{array}{c}\text { A entrada de IDE } \\
\text { proporciona a exportação }\end{array}$ & Corrente, médio \\
\hline 8. Dimensão & Nacional-Global & $\begin{array}{l}\text { Regional-nacional - } \\
\text { global }\end{array}$ & $\begin{array}{l}\text { Declinante; serviços } \\
\text { expandindo se na } \\
\text { internacionalização. }\end{array}$ \\
\hline
\end{tabular}

Quadro 1: Características de diferenciação da inovação na indústria e no serviço

Fonte: Adaptação de Howells, 2000.

As principais diferenças das características apresentadas no Quadro 1 entre produtos e serviços ficam para a intangibilidade dos serviços, o que se entrega ao cliente final e como cada um influência na importação e ou na exportação de Investimento Direto Estrangeiro.

Gallouj (2002) assume que a inovação em serviços abrange três vertentes principais: a tecnicista, a orientada para serviços e a integradora. A abordagem tecnicista iguala ou reduz a inovação em serviços à introdução de sistemas tecnológicos (como exemplo, sistemas de informação e comunicação), nas empresas de serviços e organizações. A abordagem orientada para serviços procura identificar qualquer particularidade na natureza da organização que conduza a inovação em serviços. E a abordagem integradora, busca analisar os pontos convergentes entre bens e serviços, no qual a inovação é investigada de forma similar nos dois casos.

Tigre (2006) apresenta alguns dos resultados que são esperados na aplicação de uma inovação em serviços: (i) a obtenção de maior flexibilidade com intuito de atender as necessidades individuais dos clientes; (ii) promover uma maior interação entre o usuário e o fornecedor; (iii) desenvolver maior confiança do serviço e torná-lo mais tempo disponível; (iv) aumentar a agilidade de produção e diminuir o prazo de entrega do serviço; (v) zelar pelo cumprimento de normas, padrões e atentar-se para as normas de segurança; (vi) aumentar a produtividade na prestação de serviço.

Por suas características básicas, as inovações em serviços apresentam-se muito mais na forma incremental do que radical. Dessa forma, o tempo de desenvolvimento se torna menor, quando não há necessidade de busca científica, influenciando o seu surgimento (SUNDBO; GALLOUJ, 2000). O que implica em se ter ambientes que promovam tais inovações, visto que as mesmas são promovidas por aqueles que executam e entregam o serviço aos consumidores. 
Desenvolvimento de um Ambiente Propício para Inovação no Setor de Serviços:

uma Análise em Empresas de Serviços Contábeis do Vale do Itajaí - SC

\subsection{Ambiente propício a inovação}

As diferentes formas de organizações influenciam de diversas maneiras o ritmo e o tipo de inovação, conforme as características do seu ambiente. Por exemplo, organizações com estruturas rígidas são menos propensas a serem inovadoras, pois não apresentam ambientes mais formais e controlados. Já as empresas com estrutura flexível possuem mudanças técnicas e mercadológicas rápidas (BARBIERI, 2003).

Segundo Barbieri (2003) a percepção de um ambiente de inovação está conectado com fatores como: eficiência percebida com a inovação; nível de incerteza que envolve a inovação; escassez de recursos; padronização de procedimentos; grau de influência nas decisões; expectativa de prêmios e sanções; liderança de influência nas decisões; liberdade de expressar as suas dúvidas e aprendizagem encorajada, que consistentemente aparecem no ambiente interno das organizações e obtém sucesso.

Além disso, características como descentralização; desburocratização; ênfase nos resultados, na criatividade e no objetivo; orientação para mercado e para o futuro; recompensas pelo trabalho realizado; redução de níveis hierárquicos; redução do papel de staff corporativo; mudança no estilo gerencial "facilitar e autorizar"; autonomia; sistemas sofisticados de comunicação interna; uso de grupos ad hoc (interdivisional e interfuncional) e; recursos humanos internos para disseminação de conhecimento fazem parte de um ambiente propício a inovação (AHMED, 1998; PETTIGREW; MASSINI, 2003).

Um ambiente inovador e desafiador necessita de pessoas talentosas e liberdade para criatividade (AHMED, 1998; KANTER et al., 1998). Para Van de Ven (1986, p. 591) “o processo de inovação é definido como o desenvolvimento e a implementação de novas ideias por pessoas que, ao longo do tempo, se envolve em transações com outras, dentro de um contexto institucional". Sendo assim, esse ambiente pode emergir de forma não intencional, decorrente de um modelo de gestão participativa com grande abertura entre os canais de comunicação internos, (MACHADO; MORAES, 2002; MACHADO, 2007).

Criar, manter ou desenvolver ambientes propícios à inovação, é uma tarefa difícil, pois envolve mais do que estrutura, é necessário um compartilhamento de valores e pressupostos, para sua efetiva realização. Contudo, algumas empresas conseguiram desenvolver tais ambientes, entre elas temos a 3M Company, a IBM Corporation e a General Eletric - GE, que possuem em suas culturas aspectos relacionados à inovação.

A3M Company disponibiliza aos funcionários $15 \%$ do seu tempo para o desenvolvimento de projetos autodirigidos. Encoraja a conversa interdepartamental (formal e informalmente), criando um compartilhamento de informações sobre projetos e tecnologias, com o intuito de estabelecer uma cultura criativa e inovadora. Utiliza-se também de Fóruns, nos quais são debatidas ideias, projetos, problemas, experiências e façanhas. Além disso, oferece prêmios e recompensas não só aos gerentes, mas a todos aqueles que ajudam a criar novas oportunidades. A empresa pretende com isso ser a mais inovadora do mundo (KANTER et al., 1998).

A IBM Corporation adota a inovação como valor para seus funcionários, e para isso, distanciou a tomada de decisão da matriz, da alta administração corporativa e das cadeias verticais de comando, dando mais autonomia para trabalhos com outros pares, possibilitando tomadas de decisão em níveis mais baixos e maior velocidade na execução de projetos. Para 
essa empresa, algumas vezes, o melhor que a gerência pode fazer, é se manter afastada, para que o processo criativo possa ser liberado, estimulando ideias e proporcionando um ambiente mais desafiador (KANTER et al., 1998).

A General Eletric - GE organiza suas equipes de forma multifuncionais, que incluem representantes de pesquisa, marketing, manufatura, engenharia e assistência técnica, bem como vendedores e clientes, esse grupo é chamado de workout. A empresa certifica-se que as opiniões de diferentes especialistas sejam ouvidas para o desenvolvimento de uma inovação. Sua meta é ser uma empresa sem fronteira (KANTER et al., 1998).

Portanto o processo de inovação depende de muitos fatores, tais como as características do setor, as oportunidades tecnológicas percebidas, a acumulação anterior de conhecimento, entre outros. Tanto fatores internos à organização como externos a ela influenciam neste processo. Para Damanpour (1991), a inovação é um meio de mudar uma organização, em consequência de seu ambiente interno ou externo ou como uma ação pró-ativa para influenciar um ambiente.

\subsection{Estudos relacionados à inovação em serviços}

Foram encontrados 198 artigos com o tema inovação, após pesquisa realizada em 116 periódicos de alto impacto, brasileiros, classificados pelo sistema Qualis da CAPES, A1, A2, B1 e B2, da área de administração, contabilidade e turismo, no período de 2006 a 2010. Como critério de busca, pesquisou-se a palavra "inovação" no título, no resumo e nas palavras-chave. Dos 198 artigos encontrados, 41 deles tratavam a inovação sob a perspectiva micro organizacional. Destes, buscou-se os que tinham como objeto de estudo "empresas de serviços", restando apenas dois artigos. Com intuito de fortalecer os achados deste estudo, foi realizada uma nova busca na base de dados do EnAnpad dos anos de 2008 a 2010, no qual foram encontrados mais sete artigos, totalizando nove. O resultado da pesquisa apresenta-se no Quadro 2.

\begin{tabular}{|c|c|c|c|c|}
\hline & Autor & Objetivo & Metodologia & Resultados \\
\hline 1 & Vargas (2007) & $\begin{array}{l}\text { Abordar o processo de } \\
\text { inovação em } \text { erviços, } \\
\text { discutindo se o mesmo } \\
\text { possui um caráter endógeno } \\
\text { ou exógeno. }\end{array}$ & $\begin{array}{l}\text { Estudo } \\
\text { de caso }\end{array}$ & $\begin{array}{l}\text { Os resultados apontam que o processo de } \\
\text { inovação nos casos estudados é endógeno e que } \\
\text { as diferenças verificadas na trajetória de cada } \\
\text { organização estão associadas às estratégias } \\
\text { adotadas segundo as estruturas de governança } \\
\text { específicas em que cada uma está inserida, e } \\
\text { não com o impacto das inovações advindas da } \\
\text { indústria. }\end{array}$ \\
\hline 2 & $\begin{array}{c}\text { Bernardes; } \\
\text { Andreassi } \\
\text { (2008) }\end{array}$ & $\begin{array}{l}\text { Analisar o processo de } \\
\text { inovação em serviços, } \\
\text { aplicado pela nova tomada } \\
\text { de campo realizado pela } \\
\text { PAEP/2001, discutindo } \\
\text { os seus obstáculos } \\
\text { metodológicos e conceituais, } \\
\text { assim como os seus } \\
\text { resultados, tendo como base } \\
\text { comparativa a inovação na } \\
\text { indústria. }\end{array}$ & Não consta & $\begin{array}{l}\text { A taxa de inovação em serviços é inferior à taxa } \\
\text { de inovação na indústria, sendo inferior também } \\
\text { o desenvolvimento interno da inovação, } \\
\text { caracterizada mais pela contratação externa de } \\
\text { P\&D. }\end{array}$ \\
\hline 3 & $\begin{array}{c}\text { Moreira; } \\
\text { Vargas (2009) }\end{array}$ & $\begin{array}{l}\text { Investigar a relação entre } \\
\text { a prestação de serviços } \\
\text { de software ao governo } \\
\text { federal e o surgimento de } \\
\text { inovações nas empresas } \\
\text { desenvolvedoras. }\end{array}$ & $\begin{array}{c}\text { Estudo de } \\
\text { casos múltiplos }\end{array}$ & $\begin{array}{l}\text { Os resultados apontam surgimento de inovações } \\
\text { no atendimento a clientes governamentais } \\
\text { mesmo quando não há intencionalidade em sua } \\
\text { indução. As soluções inovadoras desenvolvidas } \\
\text { mostram-se mais voltadas ao atendimento } \\
\text { a parâmetros burocráticos que à obtenção } \\
\text { de benefício econômico, o que restringe sua } \\
\text { difusão no mercado e limita sua aplicação à } \\
\text { esfera governamental. }\end{array}$ \\
\hline
\end{tabular}


Desenvolvimento de um Ambiente Propício para Inovação no Setor de Serviços:

uma Análise em Empresas de Serviços Contábeis do Vale do Itajaí - SC

continuação

\begin{tabular}{|c|c|c|c|c|}
\hline 4 & $\begin{array}{l}\text { Barzotto; } \\
\text { Machado; } \\
\text { Loesch; } \\
\text { Fachin (2009) }\end{array}$ & $\begin{array}{l}\text { Caracterizar o ambiente de } \\
\text { inovação de uma instituição } \\
\text { hospitalar do oeste do Estado } \\
\text { do Paraná. }\end{array}$ & $\begin{array}{l}\text { Descritivo } \\
\text { Exploratória }\end{array}$ & $\begin{array}{l}\text { a instituição hospitalar pesquisada apresenta } \\
\text { características de ambiente inovador e que as } \\
\text { dimensões padronização dos procedimentos, } \\
\text { estrutura de mercado, concorrência e } \\
\text { comunicação foram as que mais corroboraram } \\
\text { para sua acreditação }\end{array}$ \\
\hline 5 & $\begin{array}{c}\text { Moreira; } \\
\text { Vargas }(2010)\end{array}$ & $\begin{array}{l}\text { Investigar casos de inovações } \\
\text { desenvolvidas por empresas } \\
\text { prestadoras de serviços } \\
\text { de software ao governo } \\
\text { como resposta a requisitos } \\
\text { estabelecidos de contratação } \\
\text { pública. }\end{array}$ & $\begin{array}{c}\text { Estudo de } \\
\text { casos múltiplos }\end{array}$ & $\begin{array}{l}\text { As análises de suas descrições revelam que as } \\
\text { inovações surgiram como resposta aum requisito } \\
\text { (ou conjunto de requisitos) estabelecido por um } \\
\text { cliente público e ocorreram em dois momentos: } \\
\text { pré-venda e fase de desenvolvimento. }\end{array}$ \\
\hline 6 & $\begin{array}{l}\text { Isidoro-Filho; } \\
\text { Guimarães; } \\
\text { Pacheco; } \\
\text { Silva; } \\
\text { Puccinelli } \\
\text { (2010) }\end{array}$ & $\begin{array}{l}\text { Descrever a adoção de } \\
\text { inovações baseadas em } \\
\text { Novas Tecnologias de } \\
\text { Informação e Comunicação } \\
\text { no serviço hospitalar e } \\
\text { identificar competências } \\
\text { profissionais advindas dessas } \\
\text { experiências. }\end{array}$ & $\begin{array}{l}\text { Estudo } \\
\text { descritivo } \\
\text { de casos }\end{array}$ & $\begin{array}{l}\text { Foram identificadas três inovações, implantadas } \\
\text { há, pelo menos, um ano: prontuário eletrônico } \\
\text { do paciente (PEP), sistema de gestão de } \\
\text { unidades de tratamento intensivo (SGUTI) e sala } \\
\text { inteligente de cirurgia (SIC). Em adição, foram } \\
\text { identificadas competências específicas advindas } \\
\text { de mudanças nas características técnicas dos } \\
\text { serviços, e competências transversais oriundas } \\
\text { dos impactos das inovações nos hospitais. }\end{array}$ \\
\hline 7 & $\begin{array}{l}\text { Gobara; } \\
\text { Rossoni; } \\
\text { Kato; Dossa; } \\
\text { Hocayen-da- } \\
\text { Silva (2010) }\end{array}$ & $\begin{array}{l}\text { Verificar como as dimensões } \\
\text { da cultura organizacional } \\
\text { impactam na inovação } \\
\text { das empresas de serviços, } \\
\text { especificamente aquelas do } \\
\text { setor hoteleiro. }\end{array}$ & $\begin{array}{l}\text { Descritivo } \\
\text { Exploratória }\end{array}$ & $\begin{array}{l}\text { Aanálise das variáveis que tratavam da cultura da } \\
\text { inovação demonstrou que esta apresenta caráter } \\
\text { multidimensional, cujas dimensões elucidadas } \\
\text { são: suporte à inovação; propensão ao risco; } \\
\text { e propensão à geração de ideias. Verificou-se } \\
\text { que tais dimensões afetam significativamente a } \\
\text { inovação das empresas de serviços hoteleiros, } \\
\text { com influência mais relevante nas inovações } \\
\text { gerenciais e ad hoc, evidenciando que práticas } \\
\text { gerenciais voltadas para a inovação tendem a ter } \\
\text { impacto efetivo. }\end{array}$ \\
\hline 8 & $\begin{array}{l}\text { Lima; Vargas } \\
(2010)\end{array}$ & $\begin{array}{l}\text { Situar a discussão atual sobre } \\
\text { inovação no setor público no } \\
\text { Brasil e contrastá-la com } \\
\text { estudos sobre inovação em } \\
\text { serviços, visando identificar } \\
\text { oportunidades de pesquisa. }\end{array}$ & $\begin{array}{l}\text { Levantamento } \\
\text { bibliográfico }\end{array}$ & $\begin{array}{l}\text { As possibilidades de pesquisa sobre inovações } \\
\text { no setor público são amplas, considerando- } \\
\text { se a pouca produção nacional na área. As } \\
\text { contribuições mais evidentes que a literatura } \\
\text { de inovação em serviços pode fazer referem- } \\
\text { se à representação do produto dos serviços } \\
\text { em termos de vetores de características e } \\
\text { competências; a abordagem convencional de } \\
\text { avaliação dos serviços e; a análise do processo } \\
\text { de inovação pela actor-network theory (ANT). }\end{array}$ \\
\hline 9 & $\begin{array}{c}\text { Bohrer; Vargas } \\
(2010)\end{array}$ & $\begin{array}{l}\text { Contribuirparaaidentificação } \\
\text { e caracterização de processo } \\
\text { de P\&D, tendo como objeto } \\
\text { de análise atividades de P\&D } \\
\text { em serviços hospitalares, } \\
\text { desenvolvidas por hospitais } \\
\text { universitários brasileiros e } \\
\text { que resultaram em serviços } \\
\text { inovadores. }\end{array}$ & $\begin{array}{l}\text { Estudo } \\
\text { de caso }\end{array}$ & $\begin{array}{l}\text { Constatou-se que mesmo os trabalhos que } \\
\text { propõem alguma adaptação das medidas } \\
\text { industrialistas de P\&D precisam avançar na } \\
\text { identificação e mensuração destas atividades. }\end{array}$ \\
\hline
\end{tabular}

Quadro 2: Estudos relacionados à inovação em serviços

Fonte: Dados da pesquisa.

Observa-se que os artigos encontrados são de recente publicação, sendo o mais antigo de 2007. Além disso, dos nove estudos, cinco deles possuem a participação do autor Vargas, demonstrando que os estudos nesta área ainda são incipientes e que precisam de novas pesquisas para sua consolidação.

Dos artigos levantados, sete deles $(2,3,5,6,8$ e 9$)$ apresentam resultados relacionados ao desenvolvimento da inovação, demonstrando como o cliente influência neste processo, ou ainda, como a inovação altera as atividades internas dos colaboradores. $\mathrm{O}$ foco está na inovação e não no ambiente que a favoreceu.

O ambiente propício à inovação, tema deste estudo, foi constatado nos artigos 1 , 
4 e 7. Os autores Vargas (2007), Barzotto et al. (2009) e Gobara et al. (2010) estabeleceram uma relação entre a governança e o resultado da inovação. Segundo Barzotto et al. (2009), dimensões tais como, padronização dos procedimentos, estrutura de mercado, concorrência e comunicação são características de um ambiente inovador no hospital pesquisado por eles. Já nos estudos de Gobara et al. (2010), a cultura organizacional apresentou dimensões que afetam significativamente a inovação das empresas de serviços hoteleiros, sendo elas: suporte à inovação; propensão ao risco; e propensão à geração de ideias.

\section{PROCEDIMENTOS METODOLÓGICOS}

Considerando que o principal objetivo deste estudo é verificar a percepção dos colaboradores e gestores de escritórios contábeis no que se refere a ambientes propícios ao desenvolvimento de inovação, escolheu-se realizar uma pesquisa quantitativa descritiva transversal, por meio de levantamento de dados primários, com a aplicação de questionário e perguntas fechadas. Segundo Oliveira (2001), a pesquisa quantitativa é uma investigação empírica cuja finalidade é delinear ou analisar fenômenos, avaliar programas ou isolar variáveischave. Essa pesquisa descreve as situações, utilizando critérios quantitativos que estabelecem proporções e correlações entre as variáveis observadas, procurando elementos que permitam a comprovação das hipóteses. Para Hair Jr et al. (2005), os planos da pesquisa descritiva se formam no intuito de medir características de um determinado construto teórico.

A presente pesquisa possui características que se referem às dimensões de ambiente de inovação, aquelas que favorecem o surgimento das mesmas, utilizando-se para isto a metodologia Minnesota Innovation Survey (MIS) da Universidade de Minessota nos Estados Unidos. O instrumento de coleta engloba 29 dimensões que caracterizam um ambiente inovador. Essas dimensões se encontram descritas nos estudos de Van de Ven e Chu (1989). O questionário utilizado foi adaptado do modelo proposto pelo $M I S$, mantendo os mesmos construtos, mas excluindo questões que não faziam parte da realidade dos funcionários sujeitos sociais da pesquisa. Esse questionário adaptado contemplou 21 dimensões, como segue:

\begin{tabular}{|c|l|c|}
\hline \multicolumn{1}{|c|}{ Dimensão } & Questões \\
\hline 1 & Eficiência da inovação percebida & 1 e 2 \\
\hline 2 & Nível de incerteza que envolve a inovação & $39,40,41$ e 42 \\
\hline 3 & Escassez de recursos & $29 \mathrm{a}, 29 \mathrm{~b}, 29 \mathrm{c}, 29 \mathrm{~d}$ \\
\hline 4 & Padronização de procedimentos para desenvolver a inovação & $33 \mathrm{a}$ e 33b \\
\hline 5 & Grau de influência sobre decisões & $30 \mathrm{~b}, 30 \mathrm{c}$ e $30 \mathrm{~d}$ \\
\hline 6 & Expectativas de prêmios e sanções & $4^{\mathrm{a}}$ e 5 \\
\hline 7 & Liderança do time de inovação & 6,8 e 9 \\
\hline 8 & Liberdade para expressar dúvidas & 11 e 12 \\
\hline 9 & Aprendizagem encorajada & 15 e 16 \\
\hline 10 & Dependência de recursos & 18 e 19 \\
\hline 11 & Formalização no relacionamento & $20^{\mathrm{a}}$ \\
\hline 12 & Eficiência percebida com o relacionamento & 23 \\
\hline 13 & Influência entre grupos & $24 \mathrm{a}$ e $24 \mathrm{~b}$ \\
\hline 14 & Frequência da comunicação & $34 \mathrm{c}$ e 34d \\
\hline 15 & Problemas identificados & $37 \mathrm{a}, 37 \mathrm{c}$ e 37f \\
\hline 16 & Conflitos & $35 \mathrm{a}$ e 35b \\
\hline 17 & Processos de resolução de conflitos & $38 \mathrm{a}, 38 \mathrm{c}$ e 38d \\
\hline 18 & Complementaridade & 25 e 26 \\
\hline 19 & Consenso/conflito & 27 e 28 \\
\hline 20 & Frequência da comunicação entre grupos & 36 \\
\hline 21 & Duração do relacionamento & 45 \\
\hline
\end{tabular}

Quadro 3: Dimensões questionário adaptado $M I S$

Fonte: Van de Ven e Chu (1989) 
Por se tratar de uma pesquisa que visa avaliaro ambiente propício para o desenvolvimento de inovações no setor de serviços, o questionário foi aplicado em cinco escritórios contábeis da cidade de Gaspar, localizada no Vale do Itajaí, Santa Catariana. No qual três deles possuem onze funcionários, um nove, e o último oito. Totalizando 50 (cinquenta) funcionários e respondentes para esta pesquisa, tendo como método de coleta de dados levantamento ou survey. $\quad \mathrm{O}$ s dados obtidos por meio dos questionários foram tabulados em planilha do software Microsoft Excel (C), tendo as perguntas agrupadas às dimensões às quais pertencem. Cada dimensão obteve uma média que correspondeu ao somatório das respostas das perguntas da dimensão por respondente e foi dividido pela quantidade de perguntas daquela dimensão. A base de dados contida na planilha do Excel foi importada pelo software estatístico SPSS (Statistical Package for the Social Sciences).

$\mathrm{Na}$ análise dos dados, foi utilizada a técnica Análise Fatorial com extração de fatores por meio de Análise de Componentes Principais (ACP), pois a mesma permite condensar ou resumir varias questões em um conjunto menor de fatores ou componentes, resultando em um novo conjunto de variáveis denominadas componentes principais, com questões interrelacionadas que identificam os padrões existentes nos dados. Para melhorar interpretação dos componentes principais foi aplicada a rotação Varimax, que possibilita reduzir as ambiguidades que frequentemente acompanham uma solução sem rotação (HAIR Jr. et al., 2005).

Foi realizado o teste de confiabilidade das respostas por meio do alfa de Cronbach, com resultado de 0,754. Este indicador aponta para o grau de convergência das respostas, ou seja, quanto menor a dispersão dos dados, maior a confiabilidade dos mesmos. Com nível recomendado de 0,70 (HAIR JR. et al., 2005).

Utilizou-se para este estudo a comunalidades superiores a $60 \%$ como critério para eliminação de variável, as quais, conforme Hair Jr. et al. (2005, p. 108) "representam a quantidade de variância explicada pela solução fatorial para cada variável". Também foram realizados testes para identificação do número de fatores necessários, observando as cargas fatoriais das dimensões e as comunalidades existentes entre elas, os quais apresentaram quatro fatores que melhor representariam o ambiente propício ao desenvolvimento de inovação.

\section{ANÁLISE E INTERPRETAÇÃO DOS DADOS}

Neste tópico serão apresentadas as métricas referentes à percepção dos funcionários sobre a existência das dimensões constantes no desenvolvimento de um ambiente inovador, detectadas por meio da aplicação do questionário adaptado com base na Metodologia MIS, desenvolvido originalmente pelo grupo de estudos da Universidade de Minnesotta, MIRP. Os dados estão apresentados conforme as dimensões encontradas, conforme segue na Tabela 1.

Inicialmente foi calculada a comunalidade, que para fins desta pesquisa, utilizaram-se como critério de seleção as variáveis com resultado superior a $60 \%$. Resultou desta seleção as seguintes dimensões D2 (nível de incerteza que envolve a inovação), D3 (escassez de recursos), D9 (aprendizagem encorajada), D11 (formalização no relacionamento), D12 (eficiência percebida com o relacionamento), D13 (influência entre grupos), D23 (problemas identificados), D25 (processos de resolução de conflitos), D26 (complementaridade), D27 (consenso/conflito) 
e D28 (frequência da comunicação entre grupos).

Tabela 1: Análise de Componentes Principais

\begin{tabular}{l|c|c}
\hline \multicolumn{3}{c}{ Communalities } \\
\hline Dimensões & Initial & Extraction \\
\hline D2 - nível de incerteza que envolve a inovação & 1,000 &, 659 \\
\hline D3 - escassez de recursos & 1,000 &, 741 \\
\hline D9 - aprendizagem encorajada & 1,000 &, 793 \\
\hline D11 - formalização no relacionamento & 1,000 &, 754 \\
\hline D12 - eficiência percebida com o relacionamento & 1,000 &, 756 \\
\hline D13 - influência entre grupos & 1,000 &, 637 \\
\hline D23 - problemas identificados & 1,000 &, 854 \\
\hline D25 - processos de resolução de conflitos & 1,000 &, 935 \\
\hline D26 - complementaridade & 1,000 &, 789 \\
\hline D27 - consenso/conflito & 1,000 &, 734 \\
\hline D28 - frequência da comunicação entre grupos & 1,000 &, 658 \\
\hline
\end{tabular}

Fonte: Dados da pesquisa

Após as dimensões separadas pela comunalidade, utilizou-se para seleção do número de componentes, o critério de Kaiser com o valor do eigenvalues superior a 1, pois conforme Hair Jr. et al. (2005), o componente deve explicar a variância de pelo menos uma variável. Neste caso foram utilizados quatro fatores que em conjunto explicam 75,541\% da variância dos dados, como destacado na Tabela 2.

Tabela 2: Eigenvalues ou autovalores

\begin{tabular}{c|c|c|c}
\hline \multirow{2}{*}{ Component } & \multicolumn{3}{|c}{ Initial Eigenvalues } \\
\cline { 2 - 4 } & Total & \% of Variance & Cumulative \% \\
\hline 1 & 4,275 & 38,862 & 38,862 \\
\hline 2 & 1,830 & 16,638 & 55,500 \\
\hline 3 & 1,186 & 10,784 & 66,284 \\
\hline 4 & 1,018 & 9,257 & 75,541 \\
\hline \multicolumn{4}{|c}{ Fonte: Dados da pesquisa } \\
\hline
\end{tabular}

Fonte: Dados da pesquisa

A partir da seleção do número de componentes, foi gerada a matriz de componentes rotacionados, com a finalidade de agrupar o maior número de variância por fator. Sendo que cada qual terá seu conjunto de variáveis correlacionadas, transformando-as em variáveis não correlacionadas, conforme Tabela 3.

Tabela 3: Matriz de componentes rotacionados - Método Varimax com KAISER normalizado

\begin{tabular}{l|c|c|c|c}
\hline \multicolumn{4}{c}{ Rotated Component Matrix a } \\
\hline & \multicolumn{3}{c}{ Component } \\
\hline D2 - nível de incerteza que envolve a inovação &,- 215 &,- 779 &,- 070 &, 021 \\
\hline D3 - escassez de recursos &, 139 &, 626 &,- 548 &, 170 \\
\hline D9 - aprendizagem encorajada &, 063 &, 080 &, 885 &, 000 \\
\hline D11 - formalização no relacionamento &, 763 &, 253 &, 235 &,- 227 \\
\hline D12 - eficiência percebida com o relacionamento &, 842 &, 046 &,- 016 &,- 209 \\
\hline D13 - influência entre grupos &, 581 &, 504 &, 166 &, 134 \\
\hline D23 - problemas identificados &,- 132 &,- 894 &,- 143 &, 134 \\
\hline D25 - processos de resolução de conflitos &,- 092 &,- 044 &,- 050 &, 960 \\
\hline D26 - complementaridade &, 868 &, 130 &, 112 &, 079 \\
\hline D27 - consenso/conflito &, 647 &, 393 &,- 275 &, 293 \\
\hline D28 - frequência da comunicação entre grupos &, 510 &, 213 &, 588 &,- 081 \\
\hline
\end{tabular}

Fonte: Dados da pesquisa

Foram destacadas as cargas com maior valor absoluto por fator. Com isso, pela Tabela 
Desenvolvimento de um Ambiente Propício para Inovação no Setor de Serviços:

uma Análise em Empresas de Serviços Contábeis do Vale do Itajaí - SC

3 é possível afirmar que as dimensões, D11 - formalização no relacionamento, D12 - eficiência percebida com o relacionamento, D13 - influência entre grupos, D26 - complementaridade e D27 - consenso/conflito, predominam no Fator 1. As D2 - nível de incerteza que envolve a inovação, D3 - escassez de recursos e D23 - problemas identificados, no Fator 2. As D9 - aprendizagem encorajada e D28 - frequência da comunicação entre grupos no Fator 3. E por último a D25 - processos de resolução de conflitos no Fator 4. O agrupamento destas dimensões em quatro fatores mostra a correlação entre as dimensões, ou seja, como elas estão intrinsecamente relacionadas entre si.

Van de Ven e Chu (1989) em seus estudos, descreveram cada uma das dimensões aqui destacadas, apresentadas no Quadro 2.

\begin{tabular}{|c|c|c|}
\hline FATOR & $\begin{array}{c}\text { ADAPTAÇÃ̄O } \\
\text { Van de Ven e Chu (1989) }\end{array}$ & DESCRIÇÃO \\
\hline \multirow{5}{*}{1} & D11 - Formalização & $\begin{array}{l}\text { Grau com que os relacionamentos com grupos externos a } \\
\text { organização são verbalizados ou documentados. }\end{array}$ \\
\hline & D12 - Efetividade Percebida & $\begin{array}{l}\text { Grau com que os indivíduos percebem que o relacionamento com } \\
\text { grupos externos vale a pena e satisfaz aos objetivos propostos e o } \\
\text { grau de responsabilidade e comprometimento com a inovação. }\end{array}$ \\
\hline & D13 - Influência & $\begin{array}{l}\text { Grau com que as partes do relacionamento mudam ou afetam, ou } \\
\text { influenciam umas as outras. }\end{array}$ \\
\hline & D26 - Complementaridade & $\begin{array}{l}\text { Grau de benefício mútuo ou sinergia entre as partes do } \\
\text { relacionamento. }\end{array}$ \\
\hline & D27 - Consenso / Conflitos & Grau de acordos/ conflitos entre as partes de um relacionamento. \\
\hline \multirow{3}{*}{2} & D2 - Incerteza da Inovação & $\begin{array}{l}\text { Grau de dificuldade e variabilidade percebido pelas pessoas } \\
\text { envolvidas na inovação na implementacão das idéias, }\end{array}$ \\
\hline & D3 - Escassez de Recursos & $\begin{array}{l}\text { Grau de competitividade na obtenção de recursos críticos para o } \\
\text { desenvolvimento da inovação. }\end{array}$ \\
\hline & D23 - Problemas Encontrados & $\begin{array}{l}\text { Refere-se às barreiras e obstáculos para o desenvolvimento da } \\
\text { inovação. }\end{array}$ \\
\hline \multirow[t]{2}{*}{3} & D9 - Aprendizagem Encorajada & $\begin{array}{l}\text { Grau com que os indivíduos percebem a organização como } \\
\text { um ambiente propício à aprendizagem, sem se preocupar com } \\
\text { retaliações por um casual fracasso. }\end{array}$ \\
\hline & $\begin{array}{l}\text { D28 - Frequência de } \\
\text { Comunicação }\end{array}$ & $\begin{array}{l}\text { Refere-se à frequência com que as partes de um relacionamento } \\
\text { estão em contato. }\end{array}$ \\
\hline 4 & $\begin{array}{l}\text { D25 - Processo de Resolução } \\
\text { do Conflito }\end{array}$ & $\begin{array}{l}\text { Refere-se ao método pelo qual o grupo de inovação utiliza para } \\
\text { resolver os desacordos e disputas do grupo de inovação. }\end{array}$ \\
\hline
\end{tabular}

Quadro 4: Dimensões Percebidas

Fonte: Van de Ven e Chu (1989)

Dessa forma foi possível interpretar o significado do agrupamento das dimensões e fornecer-lhes um novo nome para cada fator, descrito no Quadro 3.

\begin{tabular}{|c|c|c|c|}
\hline Fator & Dimensões agrupadas & \multicolumn{2}{c|}{ Nova dimensão } \\
\hline Fator 1 & D11, D12, D13, D26 e D27 & D1 & Relacionamento interno \\
\hline Fator 2 & D2, D3 e D23 & D2 & Recursos \\
\hline Fator 3 & D9 e D28 & D3 & Liderança \\
\hline Fator 4 & D25 & D4 & Resolução de Conflito \\
\hline
\end{tabular}

Quadro 5: Novas dimensões

Fonte: dados da pesquisa

As novas dimensões foram nomeadas como relacionamento interno, recursos, liderança e resolução de conflito. Sendo estes os fatores percebidos pelos funcionários pertencentes aos escritórios contábeis analisados, já evidenciados por Ahmed (1998), Pettigrew; Massini (2003); Barbieri (2003), como elementos que compõem um ambiente de inovação. 
Os escritórios contábeis pesquisados são de pequeno porte, os três maiores são compostos por onze funcionários, um com nove e o último com oito. Dessa forma, é possível inferir que os ambientes são pequenos e que a comunicação é fator crucial para a execução dos serviços ofertados.

Os serviços contábeis exigem profissionais qualificados, são orientados para serviços e encontram-se entre os informacionais. Com isso, disponibilizam conhecimento e informação especializada, fornecendo aos seus clientes uma visão geral da situação econômica e financeira de suas organizações, afetando a tomada de decisão dos mesmos (PELEIAS, 1999; KOTLER, 2000; ZARIFIAN, 2001; MILES, 2001; MARTINEZ, 2001; COLAUTO; BEUREN, 2004).

Para os entrevistados dos escritórios contábeis, a primeira dimensão percebida diz respeito ao relacionamento interno. A maneira como ele é conduzido nos escritórios, fazem toda a diferença para o desenvolvimento de inovações. Características como verbalização, comprometimento e sinergia entre as partes constituem esta dimensão e favorece a disseminação e ideias entre os pares (VAN DE VEN; CHU, 1989). Nesse sentido, a inovação é recorrente de um modelo de gestão participativa com grande abertura entre os canais de comunicação internos (MACHADO; MORAES, 2002; MACHADO, 2007).

A segunda dimensão em destaque refere-se a recursos. Podendo ser tanto humano, físico ou financeiro. A dificuldade de se obter tais recursos podem fazer com que ideias não sejam implementadas, inviabilizando novas sugestões. A inovação requer tempo, disponibilidade e recursos. Faz parte de um processo no qual a empresa vislumbra retornos a médio e longo prazo, e mesmo que algumas ideias delas não sejam efetivadas, fazem parte da aprendizagem organizacional (VAN DE VEN; CHU, 1989).

Um ambiente inovador e desafiador necessita de pessoas talentosas e liberdade para criatividade (VAN DE VEN,1986; AHMED, 1998; KANTER et al., 1998). Nesse sentido a liderança, pertencente à terceira dimensão, faz toda a diferença, pois pode promover esse ambiente com estilo gerencial de "facilitar e autorizar", fornecendo autonomia, liberdade de execução, criatividade, recompensas, além de encorajar o aprendizado entre seus subordinados. Também é função do líder resolver desacordos e disputas internas, aqui representadas na quarta dimensão como resolução de conflitos (VAN DE VEN; CHU, 1989; AHMED, 1998; PETTIGREW; MASSINI, 2003; BARBIERI, 2003).

\section{CONCLUSÃO}

Os escritórios contábeis possuem como característica fornecer algo intangível ao seu cliente, no qual o resultado final deverá possuir informações suficientes, para que o usuário se utilize desta, como ferramenta para a tomada de decisão.

O mercado encontra-se cada vez mais acirrado, e mesmo com a padronização e necessidade de atender a normas, leis, diretrizes entre outras, os escritórios contábeis precisam inovar, alinhando-se as exigências de seus clientes e buscando maior competitividade. Oferecendo serviços mais ágeis, precisos e completos.

Este estudo teve como objetivo verificar a percepção dos colaboradores e gestores de escritórios contábeis no que se refere a ambientes propícios ao desenvolvimento de inovação. Após pesquisa realizada em cinco escritórios contábeis na cidade de Gaspar situada no Vale do 
Itajaí em Santa Catarina, com 50 respondentes, pode-se concluir que as características que os mesmos percebem como influenciadores em um ambiente que promova a inovação estão ligados a D1 - relacionamento interno; D2 - recursos; D3 - liderança e D4 - resolução de conflito.

Um ambiente propício ao desenvolvimento de inovações necessita de um bom relacionamento interno, no qual as pessoas interajam e compartilhem ideias e sugestões. Também é preciso que haja disponibilidade de recursos humanos, físicos e financeiros para implementação dessas ideias, além de uma liderança que incentive e promova o seu surgimento, com equipes multidisciplinares, liberdade de expressão, autonomia, e a possibilidade do erro no desenvolvimento do processo. Os resultados desta pesquisa corroboram com a de Gobara et al. (2010), no qual os autores revelaram que para formar um ambiente inovador é necessário que haja suporte a inovação, propensão a risco e a geração de novas ideias.

A inovação em serviços é um meio de mudar a organização, influenciando o ambiente em sua produtividade, agilidade e a interação com cliente. Além disso, pode diminui o prazo de entrega do serviço, favorecendo sua competitividade no mercado.

A relevância dos achados deste estudo está em demonstrar que o ambiente organizacional pode ser um grande facilitador ou dificultador no processo de inovação e que a cultura organizacional permeia este ambiente, pois por meio dela os colaboradores serão estimulados a geração de ideias, as quais receberão um direcionamento por parte da liderança, que proverá recursos para sua realização.

Além disso, a inovação como uma ideia que colocada em prática gera um retorno para a organização, pode ocorrer em toda esfera setorial, sendo ela primária, secundária ou terciária. Evidenciando que a inovação não é privilégio do setor secundário (industrial), mas sim que está presente em toda a esfera econômica.

Como contribuição acadêmica, destaca-se a importância deste estudo em estimular a pesquisa em inovações em serviços, tema este recente e que necessita de mais estudos para comparações e análises, já que ainda está em fase de construção e debate.

As limitações deste estudo se dão pelo recorte de período e pela utilização de uma amostra restrita. Apontam-se como futuras pesquisas a necessidade de investigar escritórios contábeis de outras regiões para comparações de resultado. Além de outras áreas de prestação de serviços, para possível alinhamento sobre o tema.

\section{REFERÊNCIAS}

AFUAH, A. Innovation management: strategies, implementation and profits. New York: Oxford University Press, 2003.

AHMED, P. K. Culture and climate for innovation. European Journal of Innovation Management, v. 1, n. 1, p. 30-43, 1998.

BARBIERI, J. C. Organizações inovadoras: estudos e casos brasileiros. Rio de Janeiro: Ed. FGV, 2003. 158 p. 
BARZOTTO, L.; MACHADO, D. D. P. N.; LOESCH, C.; FACHIN, S. Ambiente de inovação em instituição hospitalar. In: Encontro da Associação Nacional de Pós Graduação e Pesquisa em Administração (EnANPAD), 2009, São Paulo. Anais... Rio de Janeiro: ANPAD, 2009.

BERNARDES, R. C.; ANDREASSI, T. Padrões setoriais de convergência e diferenciação entre indústria e serviços: o caso do Estado de São Paulo. In: Encontro da Associação Nacional de Pós-Graduação e Pesquisa em Administração (EnANPAD), 2008, São Paulo. Anais... Rio de Janeiro: ANPAD, 2008.

BERNARDES, R.; BESSA, V.; KALUP, A. Serviços na PAEP 2001: reconfigurando a agenda de pesquisas estatísticas de inovação. São Paulo Perspec, v. 19, n. 2, Jun. 2005. Disponível em: $<$ http://www.scielo.br/scielo.php?script=sci_arttext\&pid=S0102$88392005000200010 \& \operatorname{lng}=\mathrm{en} \& \mathrm{nrm}=\mathrm{iso}>$. Acesso em 05/07/2010.

BOHRER, C. T.; VARGAS, E. R. Análise e mensuração das atividades de P\&D em serviços: algumas lições do estudo de Hospitais Universitários Brasileiros. In: Encontro da Associação Nacional de Pós Graduação e Pesquisa em Administração (EnANPAD), 2010, São Paulo. Anais... Rio de Janeiro: ANPAD, 2010.

COLAUTO, R. D.; BEUREN, I. M. A Identificação de accruals no sistema de lucro contábil: o caso Parmalat Brasil. In: ENCONTRO NACIONAL DOS PROGRAMAS DE PÓSGRADUAÇÃO EM ADMINSTRAÇÃO, 28, 2004, Curitiba-PR. Anais... Curitiba: ANPAD, 2004.

DAMANPOUR, F. Organizational innovation: a meta-analysis of effects of determinants and moderators. Academy of Management Journal, v. 34, n. 3, p. 555-590, 1991.

DELAUNAY, J.; GADREY, J. Les enjeux de la societé de service. Paris: Presse de la Fondation National de Sciences Politiques, 1987.

DOSI, G. Technological paradigms and technological trajectories. Research Policy, v. 11, n. 2, p. $147-162,1982$.

DREJER, I. Identifying innovation in surveys of services: a schumpeterian perspective. Research Policy, v. 33, p. 551-562, 2004.

FRANCO, H. Contabilidade geral, 22.ed. São Paulo: Atlas, 1990.

GALLOUJ, F. Innovation in Services: The New Wealth of Nations. Cheltabom: Edward Elgaro, 2002.

GOBARA, C.; ROSSONI, L.; KATO, E. M.; DOSSA, A. A.; HOCAYEN-DA-SILVA; A. J. A influência das dimensões da cultura organizacional na inovação em serviços: uma análise do setor hoteleiro. Revista de Administração e Contabilidade da Unisinos, v. 7, n. 4, 2010.

GRÖNROOS, C. Marketing: gerenciamento e serviços: a competição por serviços na hora da verdade. Rio de Janeiro: Campus, 1993.

GUNDLING, E. The 3M Way to innovation: balancing people and profit. New York: Vintage Books, 1999.

HAIR, J. F.; ANDERSON, R. E.; TATHAM, R. L.; BLACK, W. C. Análise multivariada de 
dados. 5. ed. Tradução de Adonai Schulup Sant'Anna e Anselmo Chaves Neto. PA: Bookman, 2005.

HAMEL, G. O laboratório de inovação em gestão. Revista HSM Management, v. 58, n. 10, 2006.

HOWELLS, J. Innovation \& Services: new conceptual frameworks. The University of Manchester \& UMIST. CRIC Discussion Paper 38. August, 2000.

ISIDORO, A. F.; GUIMARÃES, T. A.; PACHECO, I. C. B. S.; SILVA; L. T. P. C.; PUCCINELLI, M. B. Inovação em serviços e competências profissionais: uma análise de múltiplos casos em hospitais privados no Distrito Federal. In: Encontro da Associação Nacional de Pós Graduação e Pesquisa em Administração (EnANPAD), 2010, São Paulo. Anais... Rio de Janeiro: ANPAD, 2010.

IUDÍCIBUS, S. Teoria da contabilidade. 6. ed. São Paulo: Atlas, 2000.

KANTER, R. M.; KAO, J. J.; WIERSEMA, F. D. Inovação: pensamento inovador na 3M, DuPont, GE, Pfizer e Rubbermaid. São Paulo: Negócio, 1998, 194 p.

KON, A. Sobre a atividade de serviços: revendo conceitos e tipologias. Revista de Economia Política, v. 19, n. 2, 1999.

KOTLER, P. Administração de marketing. 2. ed. São Paulo: Prentice Hall, 2000.

LIMA, D. H.; VARGAS, E. R. O Estado da arte sobre inovação no setor público: Como estudos de inovação em serviços podem contribuir? In: Encontro da Associação Nacional de Pós Graduação e Pesquisa em Administração (EnANPAD), 2010, São Paulo. Anais... Rio de Janeiro: ANPAD, 2010.

MACHADO, D. D. P. N. Organizações Inovadoras: Estudo dos fatores que formam um ambiente inovador. Revista de Administração e Inovação, v. 4, p. 1-35, 2007.

MACHADO, D. D. P. N; MORAES, E. A. Inovação planejada: mito ou realidade? In: BUSINESS ASSOCIATION OF LATIN AMERICAN STUDIES, 2002,Tampa, FL, Anais... Tampa: Balas, 2002.

MARTINEZ, A. L. Gerenciamento dos resultados contábeis: estudo empírico das companhias abertas brasileiras. 2001. 153 f. Tese (Doutorado em Ciências Contábeis) - Faculdade de Economia, Administração e Contabilidade, Universidade de São Paulo, São Paulo, 2001.

MILES, I. Services Innovation: a reconfiguration of innovation studies. Prest, University of Manchester. Discussion Paper, Series, 2001.

MOREIRA, M. F.; VARGAS, E. R. Compras governamentais e inovação em serviços de software. In: Encontro da Associação Nacional de Pós Graduação e Pesquisa em Administração (EnANPAD), 2009, São Paulo. Anais... São Paulo: ANPAD, 2009.

MOREIRA, M. F.; VARGAS, E. R. Compras para a inovação: uma análise de inovações induzidas por clientes públicos. In: Encontro da Associação Nacional de Pós Graduação e Pesquisa em Administração (EnANPAD), 2010, São Paulo. Anais... Rio de Janeiro: ANPAD, 2010. 
OKE, A. Innovation types and innovation management practices in service companies. International Journal of Operations \& Production Management, v. 27, n. 6, p. 564-587, 2007.

OLIVEIRA, S. L. Tratado de metodologia científica. São Paulo: Pioneira, 2001.

PEGORARO, P. R. Inovação nos serviços contábeis. 2007. Dissertação (Mestrado em Mestrado Em Tecnologia) - Universidade Tecnológica Federal do Paraná. Curitiba, 2007.

PELEIAS, I. R. Falando sobre controle interno. Revista IOB, n. 9, p. 1-6. Março, 1999.

PETTIGREW, A. M.; MASSINI, S. Innovative forms of organizing: trends in Europe, Japan and the USA in the 1990s. In: ; WHITTINGTON, R.; MELIN, L.; SANCHEZ-RUNDE, C.; BOSCH, F. A. J.; RUIGROK, W.; NUMAGAMI, T. (Org.). Innovative forms of organizing: International perspectives. Londres: Sage, 2003. p. 1-32.

SUNDBO, J.; GALLOUJ, F. Innovations as a Loosely Coupled System in Services. In: METCALFES, J. S.; MILES, I. (Org.). Innovation Systems in the Services Economy: measurement and case study analysis. Boston: Kluwer Academic Publishers, 2000. p. 43-68.

SUNDER, S. Theory of accounting and control. Ohio: South-Western Publishing, 1997.

TIDD, J., BESSANT, J.; PAVITT, K. Managing innovation: integrating technological, market and organizational change. Chichester: John Wiley and Sons, 2008.

TIGRE, P. B. Gestão da Inovação: a economia da tecnologia do Brasil, Rio de Janeiro: Essevier, 2006.

VAN DE VEN, A. H. Central problems in the management of innovation. Management Science, v. 32, n.5, p.590-607, maio de 1986.

VAN DE VEN, A. H.; CHU, Y. A psychometric assessment of the Minnesota innovation survey. In: VAN DE VEN, A. H. ANGLE e POOLE, M. S. (Org.). Research on the Management of Innovation: The Minnesota Studies, New York: Oxford University, 1989.

VARGAS, E. R.; Relação entre estratégia e Inovação em serviços: análise de casos no setor hospitalar. Revista O\&S, v. 14, n. 40, 2007.

ZALTMAN, G.; DUNCAN, R.; HOLBEK, J. Innovations and organizations. New York: Wiley, 1973.

ZARIFIAN, P. Objetivo competência: por uma nova lógica. São Paulo: Atlas, 2001. 
Desenvolvimento de um Ambiente Propício para Inovação no Setor de Serviços:

\section{ENDEREÇO DOS AUTORES:}

\section{Marcia Regina Santiago Scarpin}

Fundação Universidade Regional de Blumenau.

Rua Antonio da Veiga, 140

Victor Konder

89012-900 - Blumenau, SC - Brasil

\section{Luis Cesar Mondini}

Centro Universitário Leonardo DaVinci.

Rua Dr. Pedro Zimmerman, 385

Salto do Norte

89065-000 - Blumenau, SC - Brasil

\section{Mariana Neumann}

Waalc Psicologia Clínica, Organizacional e do Trabalho.

Rua Antônio da Veiga, 479

Victor Konder

89012-500 - Blumenau, SC - Brasil

\section{Denise Del Prá Netto Machado}

Fundação Universidade Regional de Blumenau

Centro de Ciências Sociais Aplicadas, Departamento de Administração.

Rua Antônio da Veiga, 140

Vila Nova

89010-971 - Blumenau, SC - Brasil 